H. Calsbeek, M. Rijken, M.J.T.M. Bekkers, J. Dekker, G.P. van Berge Henegouwen

School and leisure activities in adolescents and young adults with chronic digestive

disorders: impact of burden of disease.

International Journal of Behavioral Medicine: jrg. 13, 2006, nr. 2, p. 121-130

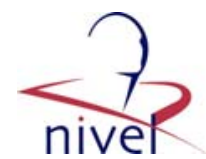

\begin{tabular}{|l|l|}
\hline Postprint Version & 1.0 \\
\hline Journal website & $\underline{\text { http://www.leaonline.com }}$ \\
Pubmed link & $\begin{array}{l}\text { http://www.ncbi.nlm.nih.gov/entrez/query.fcgi?db=pubmed\&cmd=Retrieve\&dop } \\
\mathrm{t}=\text { AbstractPlus\&list_uids=16712429\&query_hl=7\&itool=pubmed_docsum }\end{array}$ \\
\hline DOI & -
\end{tabular}

Hiske Calsbeek and Mieke Rijken, Netherlands Institute for Health Services Research (Nivel), The Netherlands; Marc J. T. M. Bekkers, PON Institute for Social Research en Development, The Netherlands; Joost Dekker, VU University Medical Centre Amsterdam, Department of Rehabilitation Medicine, The Netherlands; Gerard P. van Berge Henegouwen, University Medical Centre Utrecht, Department of Gastroenterology, The Netherlands.

This study was supported by a grant from the Foundation for Children's Welfare Stamps Netherlands. We thank Nel Feijten, Ciska Mastenbroek, Ellen Kampman, Karin Wittebrood, and Maarten Sinaasappel for their support in this study.

Correspondence concerning this article should be addressed to Hiske Calsbeek, Nivel, P.O. 1568, 3500 BN Utrecht, The Netherlands. E-mail: h.calsbeek@nivel.nl

\title{
School and Leisure Activities in Adolescents and Young Adults With Chronic Digestive Disorders: Impact of Burden of Disease
}

\author{
Hiske Calsbeek, Mieke Rijken, Marc J. T. M. BekKers, JoOst DekKer, And \\ GERARD P. VAN BERGE HENEGOUWEN
}

First, we compared the nature of burden of disease (i.e., manifestations of the disease in daily life) in adolescents and young adults with various chronic digestive disorders with controls. After that, we investigated whether burden of disease is associated with difficulties in school and leisure activities of adolescents and young adults with various digestive disorders. For this purpose, we performed a multicenter study in 5 diagnostic groups (total $N=758$; ages 12 to 25 years) including inflammatory bowel diseases (IBD), chronic liver diseases, congenital disorders, celiac disease, and food allergy and a population based control group $(N=306)$ using a self-report questionnaire. Especially adolescents and young adults with a chronic liver disease, IBD, and food allergy were found to experience daily manifestations of their disease. Several disease burden characteristics, of which especially depression, could be identified as important contributors to difficulties in school performance and leisure activities.

Due to medical advances, chronic disease has replaced acute illness as the most serious issue in pediatric medicine (Boice, 1998; Hobbs, Perrin, \& Ireys, 1985). Besides the challenges of achieving optimal growth and development, adolescents with a chronic disease must learn to manage their disease (Magrab, 1985). Adolescence is an important period in which choices are being made that are directive for future life. Having a chronic disease adds specific tasks and challenges that must be met such as learning to comply with medical treatment (Boekaerts \& Röder, 1999; Miller \& Wood, 1991).

Suffering from a chronic digestive disorder means - to a certain extent — being burdened with diet commitments, fatigue, pain, growth failure, a decreased physical condition, hospital admission, surgery, use of medication, flatulence, or incontinence. In a recent study of adult patients with inflammatory bowel diseases (IBD; Minderhoud, Oldenburg, \& van Berge Henegouwen, 2002), it was found that these patients, even in remission, were more fatigued compared with healthy controls. This tiredness correlated negatively with quality of life. The vast majority of research on the effect of chronic digestive disorders on the social position has been directed at the adult population (Bekkers, van Knippenberg, van Dulmen, van den Borne, \& van Berge Henegouwen, 1997; Bonen et al., 2002; Casellas, López-Vivancos, Badia, Vilaseca, \& Malagelada, 2001; Drossman, Patrick, Mitchell, Zagami, \& Appelbaum, 1989; Hassink, Rieu, Brugman,\&Festen, 1994; Minderhoud et al., 2002). In 
the few studies in younger populations on hand, often a noncontrolled design has been used (Akobeng et al., 1999; Rabbett et al., 1996). Nevertheless, it is clear that a chronic digestive disorder also can have a negative influence on the performance in school and leisure activities of adolescents and young adults. In Calsbeek et al. (2002), it was found that in particular being diagnosed with a chronic liver disease or IBD can have consequences for school and leisure activities: In comparison with healthy peers, these adolescents and young adults reported a higher school absenteeism due to illness and less often going out. Patients with other chronic digestive disorders (e.g., food allergy and congenital digestive disorders) were found to experience some social restrictions as well but to a lesser degree, whereas celiac disease did not appear to bring about suchlike difficulties compared with population controls.

Thus, being diagnosed with a chronic digestive disorder does not necessarily induce a worse performance in school and leisure activities. Variations as aforementioned probably can be explained by differences in the way digestive disorders manifest themselves; the burden of disease that must be met can be expected to vary between patients with various digestive disorders as well as within diagnostic groups. Although it is hard to make a priori statements on the extent of the daily manifestations of different chronic digestive disorders, it is hypothesized that chronic liver diseases and IBD are accompanied by more daily disease burden as far as, for instance, medication use or hospitalization is concerned than food allergy or celiac disease. In essence, patients with food allergy or celiac disease have to adhere to a diet. However, in case of food allergy, diets vary from one ingredient or food product to several food products. Besides, especially in youngsters, adherence to a diet can be considered an important part of the daily burden of a disease, as a daily (eating) structure is less present than in (older) adults. In addition, a diet can especially hinder social activities with peers. It is therefore hypothesized that daily burden characteristics have more impact on social activities than the medical diagnosis. More specifically, it is hypothesized that burden of disease characteristics relating to self-care activities, such as diet and medication adherence, have more impact on social activities than hospitalization and physical complaints. Insight in the associated features of school performance and leisure activities can be helpful for clinicians in more adequately supporting young patients to anticipate possible social restrictions.

Our aim in this study was twofold. First, it was to describe the nature of burden of disease in various diagnostic groups (including IBD, chronic liver diseases, congenital disorders, food allergy, and coeliac disease) with reference to population controls. Second, it was to determine whether burden of disease is associated with difficulties in school and leisure activities of adolescents and young adults with chronic digestive disorders.

\section{METHODS}

\section{Participants}

This study included 758 adolescents and young adults classified into five disease categories: IBD ( $\mathrm{n}$ $=305)$, chronic liver diseases $(n=94)$, congenital disorders $(n=137)$, food allergy $(n=98)$, and coeliac disease $(n=124)$. Mean response was $57.1 \%$, varying from $48.7 \%$ in chronic liver disease patients to $67.2 \%$ in the IBD group.We recruited patients via 25 medical specialists in 11 academic and specialized hospitals using the following criteria: being diagnosed within one of the five diagnostic categories stated by a certified medical specialist, illness duration of at least 6 months, age from 12 to 25 , being noninstitutionalized, being aware of diagnosis, not being terminally ill, being mentally capable to participate, and mastering the Dutch language sufficiently. In classifying patients into five diagnostic groups as mentioned before, we used the International Classification of Diseases (10th revision; World Health Organization, 1992). Extra patients with celiac disease needed to be recruited through a patient organization using the same criteria (diagnosis had to be confirmed by at least one small-bowel biopsy). There was no selection on illness activity or severity of complaints and disability.

We compared the various patient groups with a population- based control group including 306 controls (response rate 54.7\%). We randomly recruited these controls from the patient files of 173 general practitioners who were also the general practitioner of participating patients. In The Netherlands, (almost) every inhabitant is registered with a general practitioner. In recruiting controls, 
we used the same criteria as for the recruitment of patients except being diagnosed within one of five diagnostic categories. We provided general practitioners with a random set of three consecutive letters of the alphabet on the basis of which they were requested to select three controls with surnames each starting with one of the indicated letters and fitting the specified criteria. If with the help of these letters only one or two controls could be selected, the general practitioner was requested to continue with the next letter(s) of the alphabet.

To realize an adequate response, we reminded nonrespondents up to three times of the study. The study was approved by all participating hospitals' ethical committees. All participants gave written informed consent.

\section{Measurement}

We collected data by a mailed questionnaire. We measured four background variables: gender, age, socioeconomic status (SES), and puberty status. SES was operationalized by the highest education of one of the parents or carers on a 7-point scale ranging from 1 (no education or only primary school) to 7 (a completed university training). Puberty status was assessed by physical characteristics: having had the first menstruation in case of female respondents and the presence of a heavy voice in combination with axillary hair in male respondents.

We assessed five aspects of school and leisure activities (Calsbeek et al., 2002): school absenteeism due to illness, educational level, going out, cultural activities, and friendship. First, we measured school absenteeism by the number of whole weeks' absence during the total school period.We assessed educational level by the highest educational level at the moment of this study rated on a 7point scale ranging from 1 (no education or only primary school) to 7 (university level). We assessed going out and cultural activities by two scales derived from the Netherlands Health Interview Survey (Statistics Netherlands, 1999). The scale Going Out consisted of three items: going to the movies, going to a disco or house party, and visiting a pub (Cronbach's . =.63). Undertaking Cultural Activities was assessed by four items: visiting a library, going to a play or concert, visiting a museum, and reading books (Cronbach's.$=.63$ ).We scored all items on a 4-point scale ranging from 1 (never) to 4 (often). To facilitate interpretation, we transposed the scale scores to the same 4-point format. Finally, we assessed friendship by one scale derived from the national survey Youth and Sex (Vogels \& van der Vliet, 1990) consisting of two items: "having friends" and "undertaking activities with friends" (Cronbach's . =.64). As both items were scored on a 5-point scale ranging from 1 (no friends, no activities) to 5 (more than 10 friends, almost every day activities), we transposed the scale score to the same format to facilitate interpretation.

We assessed burden of disease by a set of eight possible tasks and challenges patients with a chronic digestive disorder can be confronted with: physical complaints, anxiety, depression, disability in endurance, hospitalization, use of medication, the need to adhere to a diet, and toilet use. We assessed physical complaints by a set of 23 complaints - for example, abdominal pain, diarrhea, skin rash, fatigue and flatulence - based on literature and brochures of physicians and patients' associations. We scored all items on a 3-point scale ranging from 0 (no trouble) to 2 (much trouble) during the last 4 weeks. We measured anxiety and depression by the Hospital Anxiety and Depression Scale (Spinhoven et al., 1997, Zigmund \& Snaith, 1983), both consisting of seven items (Cronbach's s, respectively, = .78 and .69) and scored on a 4-point scale. We assessed disability in endurance by a scale derived from the Children Quality Of Life questionnaire (Verrips et al., 1998) consisting of three items (Cronbach's . = .86): "Did you have difficulties with running the past 4 weeks," " ... with playing or sporting," and "... with running or walking for a long time (with your endurance)." We scored these items on a 3point scale ranging from 0 (no difficulties) to 2 (often difficulties; scale range $0-6$ ). We measured hospitalization by a scale existing of two items: "number of times hospital admission" and "number of times undergoing surgery" (Cronbach's . .68). We assessed daily use of medication by the number of times of medicine intake a day at the moment of this study. We measured the need to diet adherence on a 4-point scale ranging from 0 (no diet at all; "I can eat and drink what I want") to 3 (strict diet adherence; "necessary"). Finally, toilet use refers to going to the toilet at night because of bowel movement/defecation or stoma care. We assessed this measure on a 5-point scale ranging from 0 (never) to 4 (always). 


\section{Statistical Analyses}

We analyzed sociodemographic descriptives of the sample with analyses of variance or chi-square tests to test differences between groups. In analysis of variance, we used Scheffé (homogeneous groups) or Tamhane's T2 (nonhomogeneous groups) procedure.

To describe the nature of burden of disease in adolescents and young adults with various chronic digestive disorders with reference to controls (first research question), we applied analysis of covariance (one-tailed significance level of .01). In this procedure, we added age, gender, and SES as covariates, as they appeared to differ significantly between groups (see Results section) while being associated with most of the outcome measures. After that, to investigate the relationship between burden of disease and school and leisure activities (second research question), we performed two statistical procedures. First, we computed Pearson correlation coefficients between burden of disease measures and aspects of school and leisure activities in the patients group (two-tailed significance level of .01). Second, we performed multivariate regression analyses on each aspect of school and leisure activities. We carried out these regression analyses in three steps using the enter method in all steps. In the first step, we entered control variables into the regression equation (age, gender, and SES); in the second step, we entered four dummies of diagnostic groups with celiac disease as reference group; and in the final step, we entered the eight burden of disease measures into the regression model.

\section{RESULTS}

\section{Characteristics of the Participants}

In Table 1, the characteristics of each diagnostic group and the control group are summarized. The mean age in the different groups varied from 17.5 years to 20.0 years, with the IBD group being significantly older than the control group. We did not find significant differences among the diagnostic groups. The percentage female respondents varied from $47 \%$ to $69 \%$ in the various groups. We did not find significant differences between diagnostic groups and control group; we only found differences among three diagnostic groups, with the congenital disorders group showing less female participants than the food allergy and celiac disease groups. The mean score on SES varied from 3.9 to 4.8. None of the diagnostic groups differed significantly from the control group; differences only ex- isted among three diagnostic groups, with lower scores in the IBD and chronic liver disease groups compared with the celiac disease group. The percentage participants that had not reached puberty status varied from $9 \%$ to $19 \%$, which showed neither significant differences between the diagnostic groups and control group nor among the diagnostic groups.

\section{[ TABLE 1 ]}

\section{Representativeness}

Patient respondents were on the average 1 year younger than nonrespondents ( 19 and 20 years, respectively). A higher percentage was female (57\% and $48 \%$ female patients, respectively). The same pattern existed in the control group: The mean age in the respondents group was 18.5 years, compared with 20 years in nonrespondents, and $55 \%$ of the respondents were female in relation to $42 \%$ in the nonrespondents group. In addition, our controls appeared to be practically similar to several national statistics (data not shown) so that the control group was considered comparable to the Dutch population between the ages of 12 and 25 .

\section{Burden of Disease}

Table 2 displays the mean scores of burden of disease characteristics for each diagnostic group and control group. In general, respondents in all diagnostic groups were found to report significantly higher scores on one or more measures in comparison with controls. Especially the chronic liver disease group and IBD group were found to experience additional tasks and challenges due to their disease and showed significantly higher scores on many indexes compared with the control group. Both participants with a chronic liver disease and IBD experienced more physical complaints and more disability in endurance. Besides, they reported to be hospitalized more frequently, to use 
medication more often, and to watch their food intake more often than controls. Furthermore, patients with a chronic liver disease reported more anxiety and more feelings of depression. "nocturnal toilet use" appeared to be the only measure on which the chronic liver patients were found to be comparable to controls. This is in contrast with the IBD group, the only diagnostic group in which nocturnal toilet use was more present. The food allergy group also appeared to experience more disease burden compared with the control group. This includes physical complaints, disability in endurance, hospitalization, use of medication, and the need to diet adherence. In particular with regard to physical complaints, a remarkably high score was found in this diagnostic group. Compared with controls, patients with congenital digestive disorders and celiac disease reported some daily manifestations of their disease as well. Both groups were found to be hospitalized more frequently than the control group; respondents with congenital digestive disorders reported to use medication more often, whereas the celiac disease group reported the need to diet adherence more frequently.

\section{[ TABLE 2 ]}

\section{Relation Between Disease Burden and School and Leisure Activities}

Pearson correlation coefficients between burden of disease characteristics and aspects of school and leisure activities are presented in Table 3. Although most correlations were weak, significant relations were found between all school and leisure aspects on one hand and one or more burden of disease characteristics on the other hand. Most significant correlations were found with respect to friendship, school absenteeism, and educational level. Going out and undertaking cultural activities were found to be negatively correlated with only one characteristic.

\section{[ TABLE 3 ]}

Table 4 shows the results of the multivariate regression analyses of school and leisure aspects on background variables, diagnosis, and burden of disease. With regard to school absenteeism, the model explained $20 \%$ of the variance, of which the largest part was explained by disease burden. Disability in endurance, hospitalization, and the need to diet adherence were found to be significant contributors to school absenteeism. Apart from burden of disease, the diagnosis IBD showed a significant contribution to the model as well.

\section{[ TABLE 4 ]}

Regarding educational level, the model explained $23 \%$ of the variance. Background variables, in particular age and SES, accounted for the largest part of the explained variance. Apart from these characteristics, the following burden of disease measures were found to be significant contributors to a lower educational level: depression, hospitalization, and nocturnal toilet use.

With respect to going out, the regression model accounted for $12 \%$ of the variance, the largest part being explained by background variables, in particular age. However, burden of disease characteristics accounted for a small but significant part of the explained variance, with depression as the most important contributor to the regression model.

Regarding cultural activities, again $12 \%$ of the variance was found to be explained by the model, of which background variables accounted for $9 \%$ of the variance. Apart from these background variables, physical complaints and depression were identified as significant factors, with physical complaints having been a positive and depression a negative contributor to undertaking cultural activities.

Finally, with regard to friendship, the model only accounted for $7 \%$ of the variance, almost entirely explained by disease burden. Except from age, depression and disability in endurance were found to be sig- nificant contributors to the model; both were negatively related with friendship.

In sum, several burden of disease measures could be identified as associated features of difficulties in school and leisure activities taking the medical diagnosis into account. Of these, depression was found to be negatively related to most of the school and leisure aspects. More feelings of depression appeared to be an important factor of a lower educational level, less going out, less cultural activities, 
and less activities with friends. In addition, more disability in endurance was associated with higher school absenteeism and less friendship activities. More hospitalization was found to be related to a higher school absenteeism and a lower educational level. The need to diet adherence was associated with a higher school absenteeism; and finally, more nocturnal toilet use was found to be related to a lower educational level.

\section{DISCUSSION}

Our first aim in this study was to describe the nature of the burden of disease in adolescents and young adults with various chronic digestive disorders in relation to population controls. Compared with controls, results show that the respondents in all diagnostic groups scored higher on one or more characteristics of disease burden. In particular, those with a chronic liver disease, IBD, and food allergy were found to experience several daily manifestations of their disease.

A chronic liver disease can be considered a threatening disorder: Morbidity is high, and there is the prospect or undergoing of a liver transplantation. In addition, a chronic liver disease is associated with a more restrictive life expectancy. Findings in our study show that compared with the controls, young chronic liver disease patients reported more disease burden with regard to almost every measured characteristic. This includes depression and anxiety, both aspects only reported in the chronic liver disease group.

Suffering from an IBD also means that additional tasks and challenges have to be met during the transition from adolescence to adulthood. Among other gastrointestinal symptoms, IBD is usually accompanied by diarrhea, abdominal pain, weight loss, and anemia (Baldassano \& Picolli, 1999). In addition to these symptoms, adolescents may exhibit a growth failure and delayed puberty (Baldassano \& Picolli, 1999; Decker, 2000). In managing IBD, often medical and nutritional therapy and sometimes surgery is necessary. Findings of this study show that compared with population controls, adolescents with IBD experience more physical complaints, more disability in endurance, have been more frequently hospitalized, use medication more often, have to adhere to a diet more strictly, and have to use the toilet more often at night. In contrast with findings of Engstrom (1999), our IBD respondents did not appear to experience more feelings of depression or anxiety compared to the control group. According to Engstrom, depressive disorders are commonly encountered in children and adolescents with IBD. This can be explained by the character and nature of the symptoms, often socially embarrassing and hard to discuss (Engstrom, 1999). A possible explanation for the different results can be related to age: The mean age in our IBD group was 20 years (range 12-24), whereas the mean age in Engstrom's studywas 12 years (range 7-16 years). Perhaps older adolescents are psychologically better adjusted to having an IBD or less tended to report on such kind of feelings.

Adolescents and young adults with food allergy have to deal with several daily manifestations that go with their disease as well. First, the need to diet adherence can be considered an important consequence of being diagnosed with food allergy. However, apart from diet adherence, results indicate that food allergy patients used medication more often, were hospitalized more frequently, and experienced more disability in endurance compared with peers. Furthermore, surprisingly, the highest mean score on physical complaints was reported in this diagnostic group. This is not fully understood. A possible explanation is that dietary nonadherence can cause immediate allergic reactions, for example, as a consequence of the intake of only a little of a broad scale of food products. In addition, food allergy is often associated with other allergies that, as a consequence, cause additional physical complaints.

With regard to the second objective of this study, to determine whether burden of disease is associated with difficulties in schoolandleisure activities in adolescents and young adults with chronic digestive disorders, several characteristics were identified as important factors, taking medical diagnosis and sociodemographic variables into account. Surprisingly, more physical complaints appeared to be positively related to undertaking cultural activities.Apossible explanation is that cultural activities, as measured in this study, can be considered relatively quiet activities, requiring less energy and endurance. Further analysis of the separate items (data not shown)showedthat in particular, reading books and visiting a library are activities that regularly or very often are being undertaken in contrast with going to a play or concert or visiting a museum. 
Opposite, several disease burden characteristics were found to be related to difficulties in one or more school and leisure aspects. In line with our expectation, the medical diagnosis was found to play a very little part in determining school and leisure aspects. However, not so much self-care activities such as diet or medication adherence, but depressive feelings appeared to be an important factor and was associated with almost every outcome measure. In addition to depression, more disability in endurance was associated with a higher school absenteeism and less friendship activities, meaning that having energy and endurance also are important in school performance and leisure activities. Third, hospitalization appeared to be negatively associated with school absenteeism and educational level. Hospitalization was measured by a combination of the frequency of hospital admission and undergoing surgery, both consequences obviously relevant to adolescents and young adults with chronic digestive disorders. Finally, however less clearly understandable, the need to diet adherence was related to a higher school absenteeism, and more nocturnal toilet use was associated with a lower educational level. Probably other interactions play a role in these relations.

In considering these results, some methodological issues should be mentioned. A first point of attention involves the cross-sectional design of this study. From cross-sectional data, causal conclusions cannot be drawn. For example, in the negative association between depression and going out, it cannot be stated that depression is the cause of less frequently going out.

Asecond point of consideration involves the magnitude of the regression coefficients found in this study. Although they were generally small, they were consistently associated with rather distal outcome measures such as educational level and undertaking certain activities. These outcome measures involve complex events and behaviors that are usually influenced by many personal and environmental characteristics. Despite the complex nature of our outcome measures, the relations with the several burden of disease characteristics were consistent.

\section{CONCLUSIONS}

Taking these considerations into account, it can be concluded that especially adolescents and young adults with a chronic liver disease, IBD, and food allergy have to deal with additional tasks or challenges that are accompanied by their disease. Apart from sociodemographic characteristics and type of digestive disorder, several burden of disease characteristics can be considered important factors for school performance and leisure activities. This especially applies to depression. Except for depressive feelings, disability in endurance, hospitalization, need to diet adherence, and nocturnal toilet use could be identified as associated features of experiencing difficulties in school performance and leisure activities. Recognition of the importance of depression and attention for the occurrence of the previously mentioned disease burden features by parents, teachers, and doctors can be helpful in supporting adolescents and young adults with various digestive disorders to anticipate possible social restrictions.

\section{TABLES}

Table 1. Characteristics of Patients and Controls

\begin{tabular}{|c|c|c|c|c|c|c|c|}
\hline Characteristic & $\begin{array}{c}1 \\
\text { Inflammatory } \\
\text { Bowel } \\
\text { Diseasea }^{\mathrm{a}}\end{array}$ & $\begin{array}{c}2 \\
\text { Chronic Liver } \\
\text { Disease }^{\mathrm{b}}\end{array}$ & $\begin{array}{c}3 \\
\text { Congenital } \\
\text { Digestive } \\
\text { Disorder }^{c}\end{array}$ & $\begin{array}{c}\stackrel{4}{\text { Food }} \\
\text { Allergy }\end{array}$ & $\begin{array}{c}5 \\
\text { Celiac Disease }^{e}\end{array}$ & $\begin{array}{l}\text { Control } \\
\text { Group }^{f}\end{array}$ & \\
\hline Age $M(S D)$ & $20.0(3.7)^{*}$ & $19.4(4.0)$ & $18.1(3.8)$ & $18.5(3.8)$ & $17.5(3.7)$ & $18.5(3.9)$ & $F(5,1058)=11.13, p=.000$ \\
\hline Gender (\% women) & 54.8 & 56.4 & $46.7 * * 4,5$ & $69.4 * * 3$ & $64.5^{* * 3}$ & 54.9 & $\chi^{2}(5, N=1,064)=15.88, p=.007$ \\
\hline Socioeconomic status $M(S D)$ & $4.2(1.7)^{* *} 5$ & $3.9(2.0)^{* *} 5$ & $4.3(1.7)$ & $4.7(1.6)$ & $4.8(1.6)^{* * 1} 1,2$ & $4.5(1.6)$ & $F(5,1025)=4.65, p=.000$ \\
\hline Puberty status $(\%$ reached) & 86.6 & 86.7 & 81.3 & 90.8 & 88.6 & 87.8 & $\chi^{2}(5, N=1,048)=5.54, n s$ \\
\hline
\end{tabular}

$\mathrm{a}_{n}=305 . \mathrm{b}_{n}=94 . \mathrm{c}_{n}=137 . \mathrm{d}_{n}=98 . \mathrm{e}_{n=124}, \mathrm{f}_{n=306 .}$.

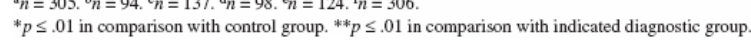


H. Calsbeek, M. Rijken, M.J.T.M. Bekkers, J. Dekker, G.P. van Berge Henegouwen School and leisure activities in adolescents and young adults with chronic digestive disorders: impact of burden of disease.

International Journal of Behavioral Medicine: jrg. 13, 2006, nr. 2, p. 121-130

Table 2. Mean Scores $( \pm S D)$ for Burden of Disease Characteristics in Patients and Controls

\begin{tabular}{|c|c|c|c|c|c|c|c|c|c|c|c|c|c|}
\hline \multirow[b]{2}{*}{ Characteristic } & \multicolumn{2}{|c|}{$\begin{array}{l}\text { Inflammatory } \\
\text { Bowel Disease }\end{array}$} & \multicolumn{2}{|c|}{$\begin{array}{c}\text { Chronic Liver } \\
\text { Disease }^{\mathrm{b}}\end{array}$} & \multicolumn{2}{|c|}{$\begin{array}{c}\text { Congenital } \\
\text { Digestive } \\
\text { Disorder }^{c}\end{array}$} & \multicolumn{2}{|c|}{ Food Allergy ${ }^{d}$} & \multicolumn{2}{|c|}{ Celiac Disease $^{e}$} & \multicolumn{2}{|c|}{ Controlst } & \\
\hline & $M$ & $S D$ & $M$ & $S D$ & $M$ & $S D$ & $M$ & $S D$ & $M$ & $S D$ & $M$ & $S D$ & \\
\hline Physical complaints (0-46) & 8.3 & $5.8^{*}$ & 6.8 & $5.7^{*}$ & 4.9 & 5.0 & 10.5 & $6.7^{*}$ & 5.5 & 4.4 & 4.4 & 3.4 & $F(5,1016)=32.85, p=.000$ \\
\hline Anxiety $(0-21)$ & 5.0 & 3.8 & 6.2 & $4.4^{*}$ & 4.5 & 3.9 & 5.1 & 3.9 & 3.7 & 3.2 & 4.3 & 3.0 & $F(5,1010)=4.59, p=.000$ \\
\hline Depression $(0-21)$ & 2.8 & 2.9 & 3.6 & $3.5^{*}$ & 2.4 & 2.7 & 2.6 & 2.5 & 2.0 & 2.2 & 2.6 & 2.5 & $F(5,1011)=2.20, p=.026$ \\
\hline Disability in endurance (0-6) & 2.3 & $2.1^{*}$ & 2.1 & $2.1 *$ & 1.3 & 1.9 & 1.9 & $2.1^{*}$ & 1.1 & 1.6 & 1.1 & 1.4 & $F(5,996)=14.40, p=.000$ \\
\hline Hospitalisation $(0-12)$ & 2.7 & $2.2^{*}$ & 3.0 & $2.6^{*}$ & 4.3 & $3.1^{*}$ & 1.6 & $1.6^{*}$ & 1.6 & $1.3^{*}$ & 1.1 & 1.4 & $F(5,977)=48.08, p=.000$ \\
\hline Use of medication $(0-4)$ & 2.4 & $1.2^{*}$ & 1.2 & $1.3 *$ & 0.5 & $1.0^{*}$ & 1.4 & $1.1^{*}$ & 0.4 & 0.9 & 0.2 & 0.6 & $F(5,987)=152.19, p=.000$ \\
\hline Need to diet adherence $(0-3)$ & 0.8 & $0.8^{*}$ & 0.7 & $0.8^{*}$ & 0.5 & 0.7 & 2.0 & $0.8^{*}$ & 2.7 & $0.8^{*}$ & 0.4 & 0.7 & $F(5,1021)=213.33, p=.000$ \\
\hline Toilet use $(0-4)$ & 0.9 & $1.1^{*}$ & 0.7 & 0.9 & 0.5 & 0.7 & 0.5 & 0.7 & 0.3 & 0.5 & 0.5 & 0.7 & $F(5,1019)=12.29, p=.000$ \\
\hline
\end{tabular}

${ }^{a} n=305 .{ }^{b} n=94 . c_{n}=137 .{ }^{d} n=98 . e_{n=124}{ }^{f_{n}}=306$

${ }^{*} p \leq .01$ (one-tailed) compared with controls after controlling for differences in age, gender, and socioeconomic status.

Table 3. Correlation Between Burden of Disease Measures and School and Leisure Aspects in Patients

\begin{tabular}{|c|c|c|c|c|c|}
\hline Measure & $\begin{array}{c}\text { School } \\
\text { Absenteeism }\end{array}$ & $\begin{array}{c}\text { Educational } \\
\text { Level }\end{array}$ & $\begin{array}{c}\text { Going } \\
\text { Out }\end{array}$ & $\begin{array}{c}\text { Cultural } \\
\text { Activities }\end{array}$ & Friendship \\
\hline Physical complaints & $.180^{*}$ & .001 & .010 & .028 & $-.123^{*}$ \\
\hline Anxiety & .064 & -.071 & .003 & -.079 & $-143^{*}$ \\
\hline Depression & .041 & $-.156^{*}$ & $-.102^{*}$ & $-.178^{*}$ & $-.229 *$ \\
\hline Disability in endurance & $.242 *$ & $-.108^{*}$ & -.075 & -.021 & $-.193^{*}$ \\
\hline Hospitalization & $.285^{*}$ & $-.134 * \mid$ & .012 & -.022 & $-.102^{*}$ \\
\hline Use of medication & $.243^{*}$ & -.066 & -.021 & .019 & $-.087^{*}$ \\
\hline Need to diet adherence & .009 & .085 & -.016 & .018 & .009 \\
\hline Toilet use & $.112^{*}$ & $-.095^{*}$ & .013 & .012 & $-.110^{*}$ \\
\hline
\end{tabular}

Note. $n=758$.

apearson correlation coefficients.

${ }^{*} p \leq .01$ (two-tailed).

Table 4. Regression of School and Leisure Aspects on Burden of Disease Measures in Patients

\begin{tabular}{|c|c|c|c|c|c|c|c|c|c|c|c|c|c|c|c|}
\hline \multirow[b]{2}{*}{ Variable } & \multicolumn{3}{|c|}{ School Absenteeism } & \multicolumn{3}{|c|}{ Educational Level } & \multicolumn{3}{|c|}{ Going Out } & \multicolumn{3}{|c|}{ Cultural Activities } & \multicolumn{3}{|c|}{ Friendship } \\
\hline & $\beta$ & $\mathrm{A} R^{2}$ & $\Delta p$ & $\beta$ & $\mathrm{A} R^{2}$ & $\Delta p$ & $\beta$ & $\mathrm{A} R^{2}$ & $\Delta p$ & $\beta$ & $\mathrm{A} R^{2}$ & $\Delta p$ & $\beta$ & $\mathrm{A} R^{2}$ & $\Delta p$ \\
\hline Background variables & & .019 & $* *$ & & .173 & ** & & .103 & ** & & .090 & ** & & .004 & $n s$ \\
\hline Age & .077 & & & $.361^{* *}$ & & & $.338^{* *}$ & & & $-.082 *$ & & & $.089^{*}$ & & \\
\hline Gender & .014 & & & .013 & & & .025 & & & $.200^{* *}$ & & & .019 & & \\
\hline Socioeconomic status & .041 & & & $.271^{* *}$ & & & .039 & & & $.208^{* *}$ & & & .045 & & \\
\hline Diagnosis $^{a}$ & & .055 & ** & & .185 & ${ }^{*}$ & & .105 & $n s$ & & .097 & $n s$ & & -.001 & $n s$ \\
\hline IBD & $.212^{*}$ & & & -.062 & & & .102 & & & -.016 & & & .175 & & \\
\hline Chronic liver disease & .054 & & & -.009 & & & -.004 & & & .060 & & & .103 & & \\
\hline Congenital digestive disorder & -.047 & & & -.054 & & & .097 & & & .077 & & & .055 & & \\
\hline Food allergy & .053 & & & .011 & & & .015 & & & .082 & & & .021 & & \\
\hline Burden of disease & & .199 & ** & & .225 & ** & & $\mid 118$ & ${ }^{*}$ & & .119 & ** & & .069 & ** \\
\hline Physical complaints & .061 & & & .088 & & & .006 & & & $.138^{* *}$ & & & .026 & & \\
\hline Anxiety & -.046 & & & -.039 & & & .070 & & & -.015 & & & .017 & & \\
\hline Depression & -.040 & & & $-.150^{* *}$ & & & $-.152^{* *}$ & & & $-.172^{* *}$ & & & $-.181^{* *}$ & & \\
\hline Disability in endurance & $.166^{* *}$ & & & -.022 & & & -.058 & & & -.018 & & & $-.135^{* *}$ & & \\
\hline Hospitalization & $.332 * *$ & & & $-.087^{*}$ & & & .004 & & & .009 & & & -.068 & & \\
\hline Use of medication & .044 & & & -.049 & & & -.026 & & & .054 & & & -.069 & & \\
\hline Need to diet adherence & $.123^{*}$ & & & -.009 & & & .053 & & & -.034 & & & .040 & & \\
\hline Noctumal toilet use & -.041 & & & $-106 * *$ & & & -.031 & & & -.022 & & & -.083 & & \\
\hline
\end{tabular}

Note. $\quad N=758 . \mathrm{A}=$ adjusted; $\mathrm{IBD}=$ inflammatory bowel disease.

With celiac disease as reference group.

${ }^{*} p \leq .05 .{ }^{* *} p \leq .01$, two-tailed.

\section{REFERENCES}

Akobeng, A. K., Suresh-Babu, M. V., Firth, D., Miller, V., Mir, P., \& Thomas, A. G. (1999). Quality of life in children with Crohn's disease: A pilot study. Journal of Pediatric Gastroenterology and Nutrition, 28, s37-s39.

Baldassano, R. N., \& Picolli, D. A. (1999). Inflammatory bowel disease in pediatric and adolescent patients. Inflammatory Bowel Disease, 2, 445-448.

Bekkers, M. J. T. M., van Knippenberg, F. C. E., van Dulmen, A. M., van den Borne, H.W., \& van Berge Henegouwen, G. P. (1997). Survival and psycho social adjustment to stoma surgery and non stoma bowel resection: A 4 years follow-up. Journal of Psychosomatic Research, 3, 235-244.

Boekaerts, M., \& Röder, I. (1999). Stress, coping and adjustment in children with a chronic disease: A review of the literature. Disability and Rehabilitation, 7, 311-317.

Boice, M. M. (1998). Chronic illness in adolescence. Adolescence, 33, 927-939.

Bonen, A., Dagnelie, P. S., Feleus, A., Hesselink, M. A., Muris, J. W., Stockbrügger, R.W., et al. (2002). The impact of inflammatory bowel disease on labor force participation: Results of a population sampled case-control study. Inflammatory Bowel Diseases, 6, 382-389. 
H. Calsbeek, M. Rijken, M.J.T.M. Bekkers, J. Dekker, G.P. van Berge Henegouwen

School and leisure activities in adolescents and young adults with chronic digestive

disorders: impact of burden of disease.

International Journal of Behavioral Medicine: jrg. 13, 2006, nr. 2, p. 121-130

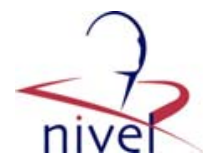

Calsbeek, H., Rijken, P. M., Bekkers, J. T. M., Kerssens, J. J., Dekker, J.,\&van Berge Henegouwen, G. P. (2002). Social posi- tion of adolescents with chronic digestive disorders. European Journal of Gastroenterology and Hepatology, 14, 543-549.

Casellas, F., López-Vivancos, J., Badia, X., Vilaseca, J., \& Malagelada, J. R. (2001). Influence of inflammatory bowel disease on different dimensions of quality of life. European Journal of Gastroenterology and Hepatology, 5, 567-572.

Decker, J. W. (2000). The effects of inflammatory bowel disease on adolescents. Gastroenterology Nursing, 2, 63-66.

Drossman, D. A., Patrick, D. L., Mitchell, C. M., Zagami, E. A., \& Appelbaum, M. I. (1989). Healthrelated quality of life in inflammatory bowel disease. Digestive Diseases and Sciences, 9, 13791386.

Engstrom, I. (1999). Inflammatory bowel disease in children and adolescents: Mental health and family functioning. Journal of Pediatric Gastroenterology and Nutrition, 28, s28-s33.

Hassink, E. A. M., Rieu, P. N. M. A., Brugman, A. T. M., \& Festen, C. (1994). Quality of life after operatively corrected high anorectal malformation: A long-term follow-up study in patients aged 18 years and older. Journal of Pediatric Surgery, 29, 773-776.

Hobbs, N., Perrin, J. M., \& Ireys, H. T. (1985). Chronically ill children and their families. San Francisco: Jossey-Bass.

Magrab, P. R. (1985). Psycho social development of chronically ill children. In N. Hobbs\&J.M. Perrin (Eds.), Issues in the care of children with chronic illness (pp. 698-716). San Francisco: Jossey-Bass.

Miller, B. D.,\&Wood, B. L. (1991). Childhood asthma in interaction with family, school and peer systems: A developmental model for primary care. Journal of Asthma, 28, 405-414.

Minderhoud, I. M., Oldenburg, B., \& van Berge Henegouwen, G. P. (2002). Severe fatigue in patients with IBD in remission [Abstract]. European Journal of Gastroenterology and Hepatology, 14, A21A22.

Rabbett, H., Elbadri, A., Thwaites, R., Northover, H., Dady, I., Firth, D., et al. (1996). Quality of life in children with Crohn's disease. Journal of Pediatric Gastroenterology and Nutrition, 23, 528-533.

Spinhoven, P., Ormel, J., Sloekers, P. P. H., Kempen, G. I. J. M., Speckens, A. E. M., \& van Hemert, A. M. (1997). A validation study of the Hospital Anxiety and Depression Scale (HADS) in different groups of Dutch subjects. Psychological Medicine, 27, 363-370.

Statistics Netherlands (CBS). (1999). Jeugd 1999. Cijfers en feiten [Youth 1999. Figures and facts]. Voorburg/Heerlen, The Netherlands: CBS.

Verrips, G. H., Vogels, A. G. C., Verloove-Vanhorick, S. P., Fekkes, M., Koopman, H. M., Kamphuis, R. P., et al. (1998). Health-Related Quality of Life Measure for Children-The TACQOL. Journal of Applied Therapeutics, 1/4, 357-360.

Vogels, T., \& van der Vliet, R. (1990). Jeugd en seks. Gedrag en gezondheidsrisico's bij scholieren [Youth and sex. Behavior and health risks in pupils]. Hague, The Netherlands: SDU.

World Health Organization. (1992). ICD-10: International statistical classification of diseases and related health problems. Geneva, Switzerland: Author.

Zigmund, A. S., \& Snaith, R. P. (1983). The Hospital Anxiety and Depression Scale. Acta Psychiatrica Scandinavia, 67, 361-370. 